\title{
Knockdown of human serine/threonine kinase 33 suppresses human small cell lung carcinoma by blocking RPS6/BAD signaling transduction
}

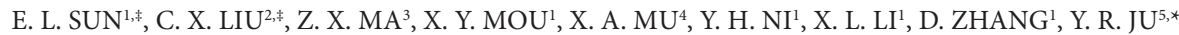

${ }^{1}$ Department of Healthcare Respiratory Medicine, Shandong Provincial Hospital Affiliated to Shandong University, Jinan, Shandong 250021, People's Republic of China; ${ }^{2}$ Department of Anesthesiology, Shandong Provincial Hospital Affiliated to Shandong University, Jinan, Shandong 250021, People's Republic of China; ${ }^{3}$ Department Respiratory Medicine, Shandong Provincial Chest Hospital, Jinan, Shandong 250013, People's Republic of China; ${ }^{4}$ Department of Foreign Language Teaching, Shandong Medical College, Jinan, Shandong 250002, People's Republic of China; ${ }^{5}$ Department of Surgical Intensive Care Unit, Shandong Provincial Hospital Affiliated to Shandong University, Jinan, Shandong 250021, People's Republic of China

${ }^{*}$ Correspondence: juyuanrong99@126.com

${ }^{*}$ Contributed equally to this work.

\section{Received November 18, 2016 / Accepted April 10, 2017}

\begin{abstract}
Small cell lung cancer (SCLC) is characterized by rapid growth rate and a tendency to metastasize to distinct sites of patients' bodies. The human serine/threonine kinase 33 (STK33) gene has shown its potency as a therapeutic target for prevention of lung carcinomas including non-small cell lung cancer (NSCLC), but its function in the oncogenesis and development of SCLC remains unrevealed. In the current study, it was hypothesized that STK33 played a key role in the proliferation, survival, and invasion of SCLC cells. The expression of STK33 in human SCLC cell lines NCI-H466 and DMS153 was inhibited by specific shRNA. The cell proliferation, cell apoptosis, and cell invasion of the cells were assessed with a series of in vitro assays. To explore the mechanism through which STK33 gene exerted its function in the carcinogenesis of SCLC cells, the effect of STK33 knockdown on the activity of S6K1/RPS6/BAD signaling was detected. Then the results were further confirmed with STK33 inhibitor ML281 and in vivo assays. The results demonstrated that inhibition of STK33 in SCLC cells suppressed the cell proliferation and invasion while induced cell apoptosis. Associated with the change in the phenotypic features, knockdown of STK33 also decreased the phosphorylation of RPS6 and BAD while increased the expression of cleaved caspase 9, indicating that apoptosis induced by STK33 suppression was mediated via mitochondrial pathway. Similar to the results of STK33 knockdown, incubating NCI-H466 cells with STK33 inhibitor also reduced the cell viability by suppressing RPS6/BAD pathways. Additionally, STK33 knockdown also inhibited tumor growth and RPS6/BAD activity in mice models. Findings outlined in our study were different from that in NSCLC to some extent: knockdown of STK33 in SCLC cells induced the apoptosis through mitochondrial pathway but independent of S6K1 function, inferring that the function of STK33 might be cancer type specific.
\end{abstract}

Key words: BAD, cleaved caspase 9, human serine/threonine kinase 33, RPS6, small cell lung cancer

As one of the most commonly recognized cancer types, lung carcinoma accounts for $10 \%$ of all the diagnosed cancer cases worldwide. According to the investigation in 2012, lung carcinoma has become the leading cause of cancer related death for males and has surpassed breast cancer as the leading cause of cancer related death for females [1]. In addition to the high incidence, the prognosis of lung carcinoma is extremely poor with an $18 \%$ five-year survival rate on average [2]. Oncogenesis of lung carcinoma can be attributed to indoor air pollution, exposure to occupational and environmental carcinogens, and outdoor pollution. Based on the morphology and genetics of cancer cells, lung carcinoma can be classified into two major types: non-small cell lung cancer (NSCLC) and small cell lung cancer (SCLC) [3]. NSCLC is commonly diagnosed in clinic and further defined as adenocarcinomas, squamous cell carcinomas, and large cell carcinomas [3]. Compared with NSCLC, SCLC only comprises $15 \%$ of all the lung carcinoma cases. Generally, SCLC is diagnosed by histology [4] and distinguished by neuroendocrine (NE) features [4]. Typical patients of SCLC are males older than 
70 years who are heavy smokers and who have pulmonary and cardiovascular comorbidities [4]. Although rarely recognized, SCLC is characterized by the most rapid growth rate among all lung carcinomas and shows a tendency to metastasize to distinct sites of the body in its early stage $[5,6]$. Furthermore, few treatment options remain for SCLC except topotecan, but the relapse rate of SCLC is high despite the high initial response rate of the therapy [4]. Thus, efforts are being made to identify signaling pathways that might yield new drug targets for SCLC.

Recurrent mutations found in cancers are commonly conceived to be the driving force for oncogenesis and progression of tumors, but such knowledge for SCLC are lagging behind due to a scarcity of research material available. Recent studies based on genomic techniques of SCLC have revealed a high frequency of gene gains and losses [7], including those specific for SCLC, i.e., the nearly uniform loss of function of the tumor suppressor TP53 and RB1 [8-11] and those common to all lung carcinomas, i.e., loss of large regions of chromosome $3 p$ [12] which represents the therapeutic potential of indicators associated with other lung carcinoma in SCLC. Thus, it is reasonable to comprehensively investigate the role of factors activated in other lung carcinomas in the tumorigenicity of SCLC. The human serine/threonine kinase 33 (STK33) gene is a member of the $\mathrm{Ca}^{2+} /$ calmodulin-dependent kinase family [13]. The expression of STK33 is restricted in healthy human adults and embryonic tissues. Nevertheless, the factor is highly expressed in some types of cancers [14, 15] and plays vital and complicated roles in the progression of these tumors. In the studies of Wang et al. and others [15, 16], STK33 has been widely studied for its 'synthetic lethal' function, which promotes cancer survival by suppressing mitochondrial apoptosis through S6K1-induced inactivation of the death agonist BAD. However, research of Babij et al. has concluded that STK33 is a potential target for treatment of KRAS mutant tumors [17]. Based on the above studies, it is demonstrated that the function STK33 in lung carcinomas remains partially uncovered, especially in SCLC in which the role of STK33 has never been explored.

Therefore, the major purpose of the current study was to investigate the function of STK33 in SCLC. By knocking down the expression of STK33 in human SCLC cell lines NCI-H446 and DMS153, the effect of STK33 on cell survival and metastasis of SCLC was determined. Moreover, the interaction between STK33 and S6K1/RSP6/BAD signaling pathway was also studied to preliminarily underlie the mechanism involving in the function of STK33 in SCLC. The results of in vitro assays were validated with a SCLC xenograft mice model as well.

\section{Materials and methods}

Chemicals, cell culture, and animals. Human SCLC cell line NCI-H446 (No. ZQ0008) were purchased from Zhongqiaoxinzhou Cell Research and cultured in cultured in DMEM medium containing $10 \%$ FBS and $1 \%(\mathrm{v} / \mathrm{v})$ antibiotics mixture at $37^{\circ} \mathrm{C}$ with $5 \% \mathrm{CO}_{2}$ and $100 \%$ humidity. Human SCLC cell line DMS153 was obtained from Institute of Basic Medicine Sciences Chinese Academy of Medical Sciences, School of Basic Medicine Peking Union Medical College and cultured in Waymouth's medium containing 10\% FBS and $1 \%(\mathrm{v} / \mathrm{v})$ antibiotics mixture at $37^{\circ} \mathrm{C}$ with $5 \% \mathrm{CO}_{2}$ and $100 \%$ humidity. Antibody against STK33 (No. D153542) was purchased from Sango Biotech, Shanghai, China. Antibodies against RPS6 (No. bs-3565R), phosphorylated RPS6 (p-RPS6) (No. bs-18828R), BAD (No. bs-1304R), and p-BAD (No. bs-0893R) were purchased from BIOSS, Beijing, China. Antibodies against S6K1 (No. \#2708), and p-S6K1 (No.\#9208), and cleaved caspase 9 (No. \#9505) were purchased from CST, USA. Goat anti-rabbit IgG-HRP antibody (No. A0208) and goat anti-mouse IgG-HRP antibody (No. A0216) were purchased from Beyotime Biotechnology, China. Antibody against $\beta$-actin (No. sc-47778) was purchased from Santa Cruz Biotech, USA. STK33 inhibitor ML281 (No. HY-13495) was purchased from MedChemExpress, USA. BALB/c-nu mice (Changsheng Biotechnology, China) were used for tumorigenicity assay and maintained in cages at room temperature $\left(20-25^{\circ} \mathrm{C}\right)$ with a constant humidity $(55 \pm 5 \%)$ with availability to food and water. All the animal experiments were performed following the Institutional Animal Ethics Committee and Animal Care Guidelines for the Care and Use of Laboratory Animals of Shandong Provincial Hospital Affiliated to Shandong University.

Construction of $S T K 33$ knockdown vector and transfection. STK33-specific shRNA (5'-GCCCTCAAGAACCTCAAAT-3') and a matched non-targeting control shRNA were ligated into pRNA-H1.1 plasmid to form pRNA-H1.1NC and pRNA-H1.1-shSTK33 plasmids for transfection. Different plasmids were transfected into SCLC cells using Liposome 2000 (No. 1024993, Invitrogen, USA) according to the manufacturers' instruction based on the following experimental designs: A) Control group, SCLC cells. B) NC group, SCLC cells transfected with pRNA-H1.1-NC plasmid. C) shSTK33 group, SCLC cells transfected with pRNAH1.1-shSTK33. Each group was represented by at least five replicates. Cells with stable STK33 knockdown were selected with G418 (200 $\mu \mathrm{g} / \mathrm{ml})$ (No 11811023, Invitrogen, USA). The expression changes of STK33 in different groups were validated using reverse transcription real time PCR ( $\mathrm{RT}^{2}$-PCR) and western blotting as described following (Supplementary Figure S1).

Inhibition of STK33 with ML281. For validation of the role of STK33 in the oncogenesis of SCLS, the activity of the gene was further inhibited by ML281 in NCI-H446 cells: A) Control group, NCI-H446 cells. B) Mock group, cells incubated with DMSO for $72 \mathrm{~h}$. C) ML281 group, cells incubated with $10 \mu \mathrm{M}$ ML281 for $72 \mathrm{~h}$. Each group was represented by at least five replicates. Then cells were collected and subjected to MTT assay and western blotting as described following.

Tumorigenicity assay. Eighteen BALB/c-nu mice were randomly divided into three groups (six for each group): A) 
Control group, mice were subcutaneously injected with $0.2 \mathrm{~mL}$ $\left(5 \times 10^{7} / \mathrm{mL}\right)$ NCI-H446 at oxter. B) NC group, mice were subcutaneously injected with $0.2 \mathrm{~mL}\left(5 \times 10^{7} / \mathrm{mL}\right)$ pRNA-H1.1NC plasmid transfected NCI-H446 cells. C) shSTK33 group, mice were subcutaneously injected with $0.2 \mathrm{~mL}\left(5 \times 10^{7} / \mathrm{mL}\right)$ pRNA-H1.1-shSTK33 plasmid transfected NCI-H446 cells. The mice were raised under the same conditions for 22 days. The volumes, major axis, and minor axis of the solid tumors were measured every three days since the $7^{\text {th }}$ day of the assay. Upon completion of the assay, all the mice were sacrificed using air embolism method and tumor tissues were harvested and preserved at $-80^{\circ} \mathrm{C}$ for western blotting.

MTT assay. Cell viabilities of SCLC cells in different groups were measured by MTT assay: briefly, exponentially growing cells $\left(3 \times 10^{3} /\right.$ well $)$ were seeded into a 96 -well plate and cultured for $120 \mathrm{~h}$. Wells in each group were randomly sampled every $24 \mathrm{~h}$ since the start of assay and $5 \mathrm{mg} / \mathrm{ml}$ MTT (No. M-2128, Sigma, USA) were added into the selected wells. After incubating for additional four hours at $37^{\circ} \mathrm{C}, 200 \mu \mathrm{DMSO}$ (No. D-5879, Sigma, USA) was added into the wells and the cell viabilities were represented by the $\mathrm{OD}_{490}$ values measured with a Microplate Reader (ELX-800, BIOTEK, USA).

Flow cytometry. The cell cycle distribution of SCLC cells under different treatments were determined using flow cytometry: briefly, $300 \mu \mathrm{l}$ Propidium Iodide (PI)-FITC was added to different wells to stain the DNA of cells in dark. After $20 \mathrm{~min}$ incubation at room temperature, the DNA contents of the cells were analyzed using a FACS flow cytometer (Accuri C6, $\mathrm{BD}, \mathrm{USA}$ ).

To assess the effect of STK33 knockdown on the apoptotic process in SCLC cells, an Annexin V-FITC Apoptosis Detection Kit (JingMei Biotech, Beijing, China) was employed according to the instructions from the manufacturers. The apoptotic rates were analyzed using a FACScan flow cytometry (Accuri C6, BD, USA). The apoptotic cell rate (UR+LR-all apoptosis cell percentage) was equal to the sum of the late apoptotic rate (UR, upper right quadrant-advanced stage apoptosis cell percentage) and the early apoptotic rate (LR, lower right quadrant-prophase apoptosis cell percentage).

Transwell assay. The transwell assay was conducted to measure the invasion ability of SCLC cells: briefly, $200 \mu \mathrm{l}$ medium containing cells $\left(2 \times 10^{4} /\right.$ well $)$ were seeded into the upper chamber of a transwell system (BSA-coated $8 \mu \mathrm{M}$ pore size with polycarbonate membrane, Corning star, Cambridge, MA). The polycarbonate membranes were previously coated with $40 \mu \mathrm{l}$ matrigel $(1.5 \mathrm{mg} / \mathrm{ml}$; BD Biosciences, San Jose, $\mathrm{CA}, \mathrm{USA}$ ) at $37^{\circ} \mathrm{C}$ for $2 \mathrm{~h}$ to form a reconstituted basement membrane. Cells were allowed to migrate through the porous membrane at $37^{\circ} \mathrm{C}$ for $24 \mathrm{~h}$. Then cells in the upper surface of the chamber were completely removed. The lower surfaces of the membranes were stained in a solution containing $0.5 \%$ $(\mathrm{w} / \mathrm{v})$ crystal violet for $5 \mathrm{~min}$ and afterwards washed using $\mathrm{ddH}_{2} \mathrm{O}$. Numbers of cells in five randomly selected fields were determined using Image-Pro Plus 6.0 software (Nikon) at $200 \times$ magnification.
Scratch assay. To evaluate cell mobility affected by STK33 knockdown, scratching assays of SCLC cells under different treatments were performed. The cells were seeded in a 24-well plate at a number of $2 \times 10^{4} /$ well with serum free medium supplemented with $1 \mu \mathrm{g} / \mathrm{ml}$ mitomycin C and cultured for $1 \mathrm{~h}$. Reference points were marked to guarantee the same area of image acquisition and plates were incubated at $37^{\circ} \mathrm{C}$. Cells were allowed to grown into confluent monolayer in complete medium for two days. Then the cell layers were scratched to form a cell-free straight line. Each well was washed with PBS for two times to remove debris from the edge of the scratch. Afterwards, the migration of cells in the "scratch" was recorded at the matching reference points. For each well, three images $(0 \mathrm{~h}, 24 \mathrm{~h}$, and $48 \mathrm{~h})$ were taken with a phase-contrast microscope. The distances between the two edges of the scratch were measured at the reference points. Wound healing was defined as the percentage of the starting distance between the two edges of each wound and data was analyzed by ImageJ software (US National Institutes of Health).

$\mathbf{R T}^{2}$-PCR. Total RNA was extracted from cells in different groups using RNA Purified Total RNA Extraction Kit according to the manufacturer's instruction (Calt. No. RP1201, BioTeke, Beijing, China). $\beta$-actin was employed as the internal reference gene. cDNA templates were achieved by reversely transcribing the RNA using Super M-MLV reverse transcriptase (Calt. No. RP6502, BioTeke, Beijing, China), and the final $\mathrm{RT}^{2}$-PCR reaction mixture of volume $20 \mu \mathrm{l}$ contained $10 \mu \mathrm{l}$ of SYS BR Primix Ex Taq 2, $0.5 \mu \mathrm{l}$ of each primers (STK33, forward: 5'-ACAAATGGCTGATAGTGGC-3', backward: 5'-GAGGTTCTTGAGGGCAAATCT-3'. $\beta$-actin, forward: 5'-CTTAGTTGCGTTACACCCTTTCTTG-3', backward: 5'-CTGTCACCTTCACCGTTCCAGTTT-3'), $1 \mu \mathrm{l}$ of the cDNA template, and $8 \mu \mathrm{l}$ of Rnase free $\mathrm{H}_{2} \mathrm{O}$. Thermal cycling parameters for the amplification were as follows: a denaturation step at $95^{\circ} \mathrm{C}$ for $10 \mathrm{~min}$, followed by 40 cycles at $95^{\circ} \mathrm{C}$ for $10 \mathrm{~s}, 60^{\circ} \mathrm{C}$ for $20 \mathrm{~s}$ and $72^{\circ} \mathrm{C}$ for $30 \mathrm{~s}$. Relative expression levels of targeted genes were calculated with Data Assist Software version 3.0 (Applied Biosystems/Life Technologies) according to the expression of $2^{-\Delta \Delta c t}$.

Western blotting assay. The total protein product in different samples was extracted using the Total Protein Extraction Kit according to the manufacturer's instructions (No. WLA019, Wanleibio, China). $\beta$-actin was used as internal reference protein. Concentrations of protein samples were determined using the BCA method, and $20 \mu \mathrm{g}$ of protein was subject to a $10 \%$ sodium dodecylsulfate polyacrylamide gel electrophoresis (SDS-PAGE) and electrophoresed for $2.5 \mathrm{~h}$ at $80 \mathrm{~V}$. After transferring targeted proteins onto polyvinylidene difluoride (PVDF) sheets, the membranes were washed with TTBS for $5 \mathrm{~min}$ and then incubated with skim milk powder solution for 1 hour. Primary antibodies against STK33 (1:500), RPS6 (1:400), p-RPS6 (1:400), S6K1 (1:1000), p-S6K1 (1:1000), cleaved caspase 9 (1:1000), BAD (1:400), and p-BAD (1:400) or $\beta$-actin (1:1000) were incubated with membranes $4^{\circ} \mathrm{C}$ overnight. After additional four washes using TTBS, secondary 
A

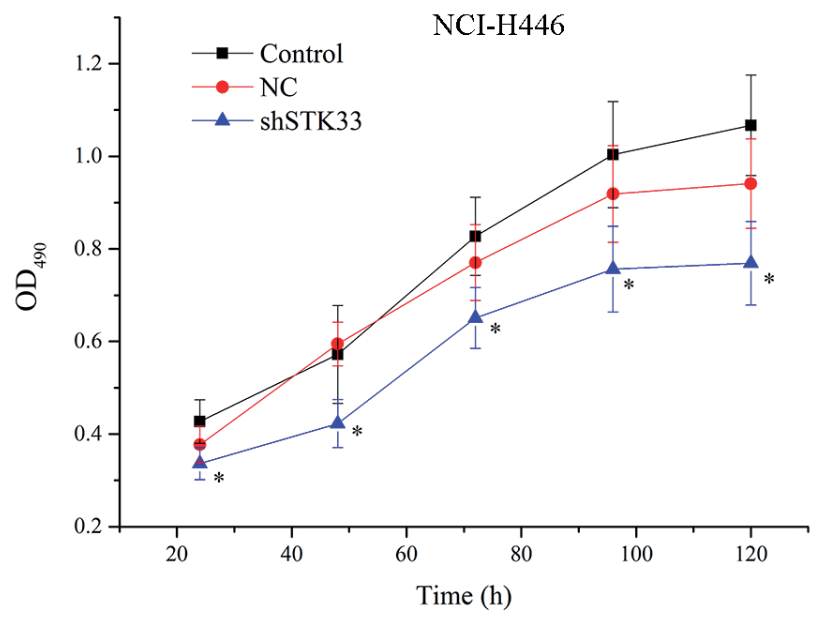

B

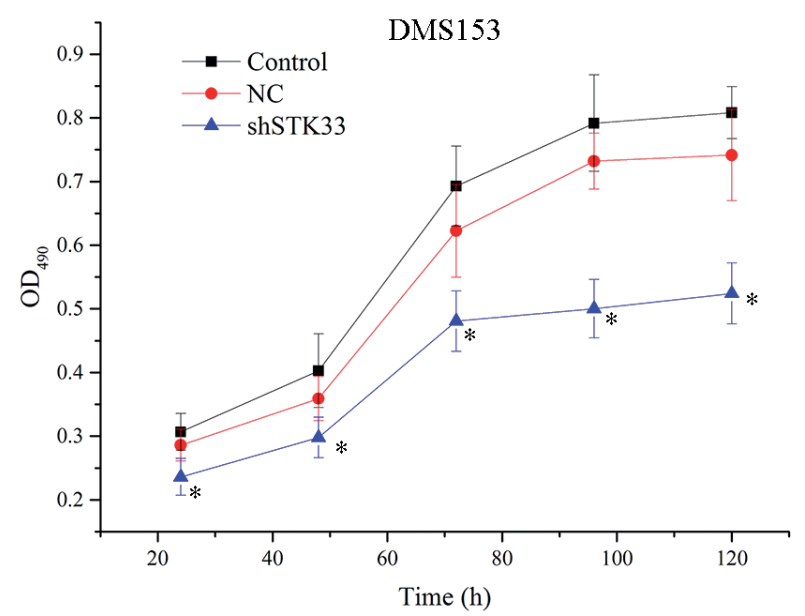

Figure 1. Knockdown of STK33 suppressed the cell viability in a time dependent manner in SCLC cells. Exponentially growing cells (3×10 3 /well) were cultured for $120 \mathrm{~h}$ and wells were randomly sampled every $24 \mathrm{~h}$ since the start of assay. A, quantitative analysis results of OD cells. B, quantitative analysis results of $\mathrm{OD}_{490}$ values of DMS153 cells. “*”, significantly different from Control group, $P<0.05$.

IgG-HRP antibodies (1:5000) were added and incubated with the membranes for $45 \mathrm{~min}$ at $37^{\circ} \mathrm{C}$. After another six washes using TTBS, the blots were developed using Beyo ECL Plus reagent and the results were recorded in the Gel Imaging System.

Statistical analysis. All the data were expressed in the form of mean \pm standard derivation (SD) $(n=5)$. One-way analysis of variance (One-way ANOVA) and multiple comparisons by LSD method were conducted with a significant level of 0.05 . Difference between two groups was analyzed using Student $\mathrm{t}$-test. All the statistical analyses and graph manipulation were conducted using OriginPro 9.0 software. 2.3.4 (Origin lab).

\section{Results}

Knockdown of STK33 decreased cell viability of SCLC cells. The effect of STK33 knockdown on the cell viability of SCLC cells was assessed in a time series experiment. The cells were incubated for $120 \mathrm{~h}$ and every $24 \mathrm{~h}$, the $\mathrm{OD}_{490}$ values in each group were recorded with MTT assays. And as illustrated in Figure 1, cell viabilities in shSTK33 group were lower than those in Control and NC groups at each time point, and the differences between shSTK33 group and the other two groups were statistically significant $(P<0.05)$, indicating the key role of STK33 in the proliferation of SCLC cells.

Knockdown of STK33 induced cell apoptosis and G1 phase cell cycle arrest in SCLC cells. Based on the results of flow cytometry detection, knockdown of STK33 induced cell apoptosis in SCLC cells (Figure 2A and Figure 2B): for Control group, the average apoptotic rates were $3.7 \pm 0.5 \%$ (NCI-H446 cells) and $2.8 \pm 0.3 \%$ (DMS153 cells), respectively. For NC group, the average apoptotic rate was $4.2 \pm 0.6 \%$ (NCI-H446 cells) and $3.7 \pm 0.6 \%$ (DMS153 cells), respecitvely. And for shSTK33 group, the average apoptotic rate was $12.7 \pm 0.6 \%$ (NCI-H446 cells) and $15.6 \pm 1.1 \%$ (DMS153 cells). According to the statistical analyses, the differences between shSTK33 groups and the other two groups were statistically significant $(P<0.05)$. Furthermore, knockdown of STK33 also induced G1 phase cell cycle arrest in NCI-H446 cells. As shown in Figure 2C and Figure 2D, average proportion of cells distributed in G1 phase in shSTK33 group $(75.5 \pm 6.9 \%$ for NCI-H446 cells and $56.4 \pm 1.1 \%$ for DMS153 cells) was higher than those in Control (62.9 $\pm 6.5 \%$ for NCI-H446 cells and $46.4 \pm 1.1 \%$ for DMS153 cells) and NC groups $(63.7 \pm 6.5 \%$ for NCI-H446 cells and $48.6 \pm 0.6 \%$ for DMS153 cell), and the difference was statistically significant $(P<0.05)$. Concatenated with the results of MTT assay, it was demonstrated that STK33 played a vital role in the survival and viability of SCLC cells, inhibition of which would dramatically inhibited the progression of the cancer.

Knockdown of STK33 inhibited the invasion potential of SCLC cells. Metastasis of malignant cancers depends critically on the invasion potential of cancer cells. Therefore, we conducted transwell and scratch assays to assess the effect of STK33 knockdown on the invasive feature of SCLC cells. And as shown in Figure 3A and Figure 3B, compared with normal SCLC cells and SCLC cells transfected with NC shRNA, the number of cells penetrating membrane in transwell assay was reduced in SCLC cells with STK33 knockdown. A similar pattern was also observed for scratch assay: the cells treated with STK33 shRNA showed a delayed process of wound closure compared with the untreated cells, representing markedly inhibited migrational movement (Figure 3C and Figure 3D), and the results were confirmed both by representative images and quantitative analyses. Taken together, STK33 not only influence the survival and proliferation of SCLC cells but also played a determinant role in the invasion potential of the cancer. 
Knockdown of STK33 exerted its function in SCLC via inactivation of RPS6/BAD signaling. To elucidate the mechanism driving the effect of STK33 knockdown on SCLC cells, the activity of S6K1/RPS6/BAD signaling was detected.
The pathway was proved to be associated with the function of STK33 in NSCLC. However, in the current study, it was found that knockdown of STK33 had no effect on the activity of S6K1 (data not shown). But the expression status of other indicators
A
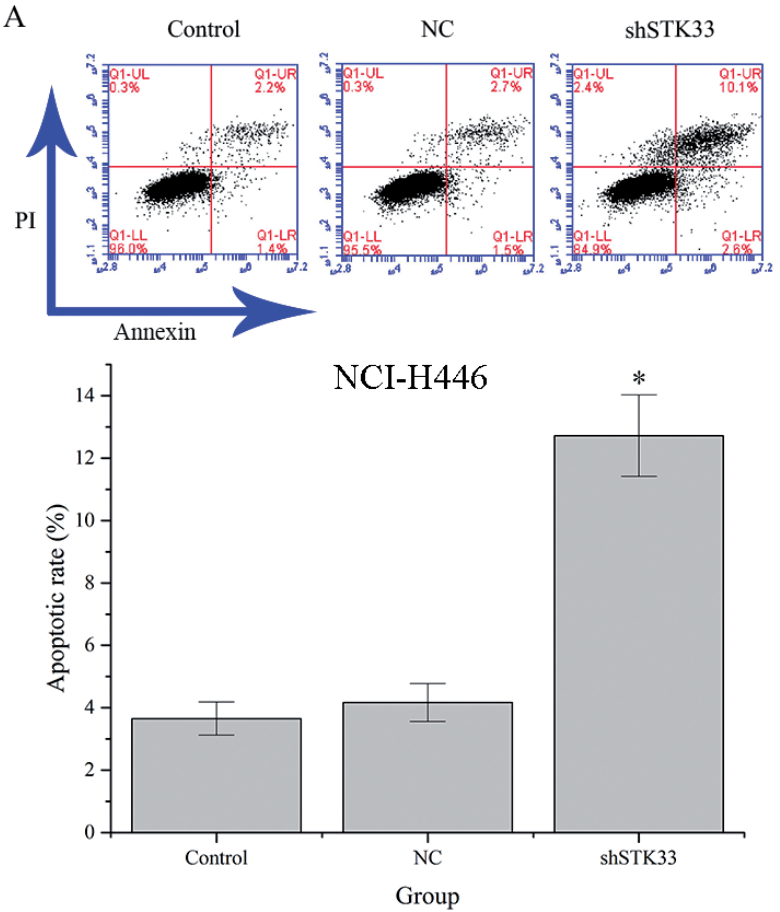

C
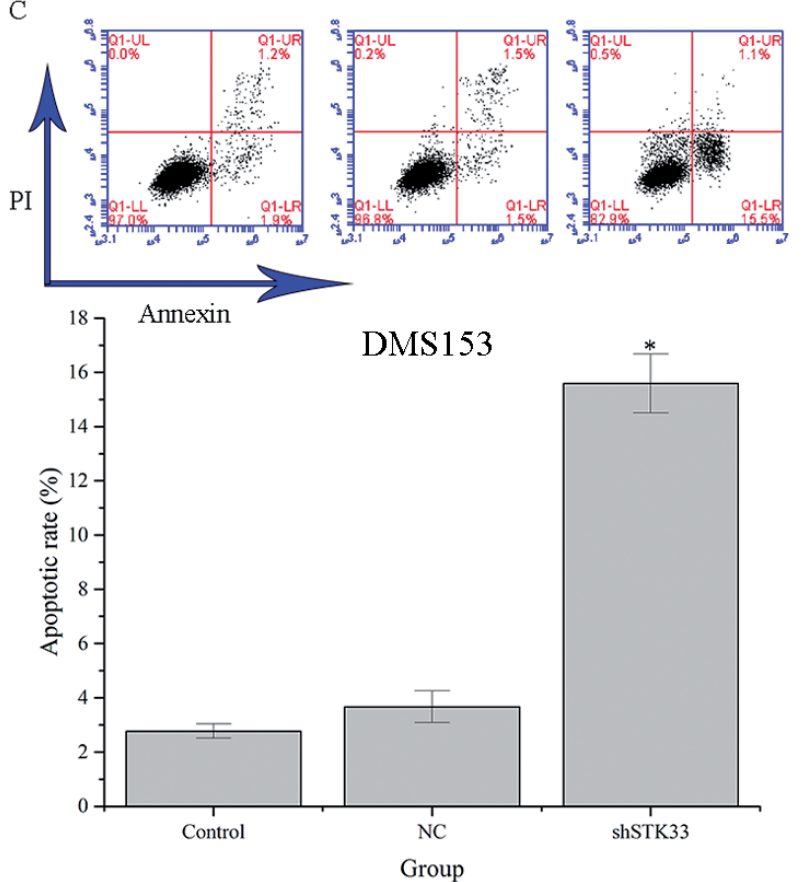

B
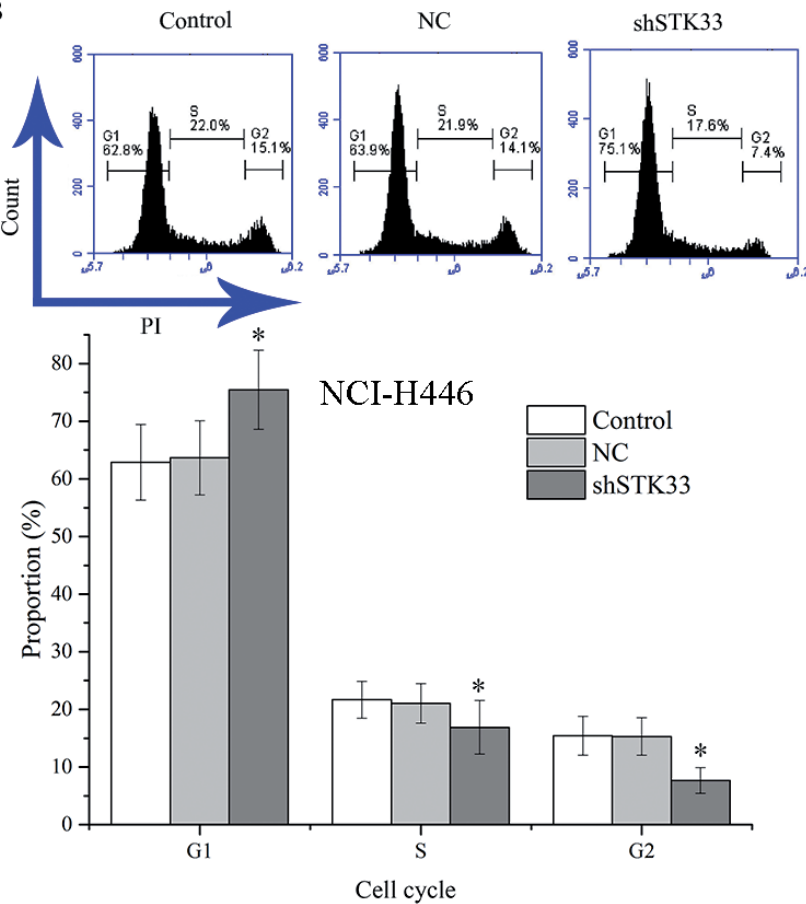

D
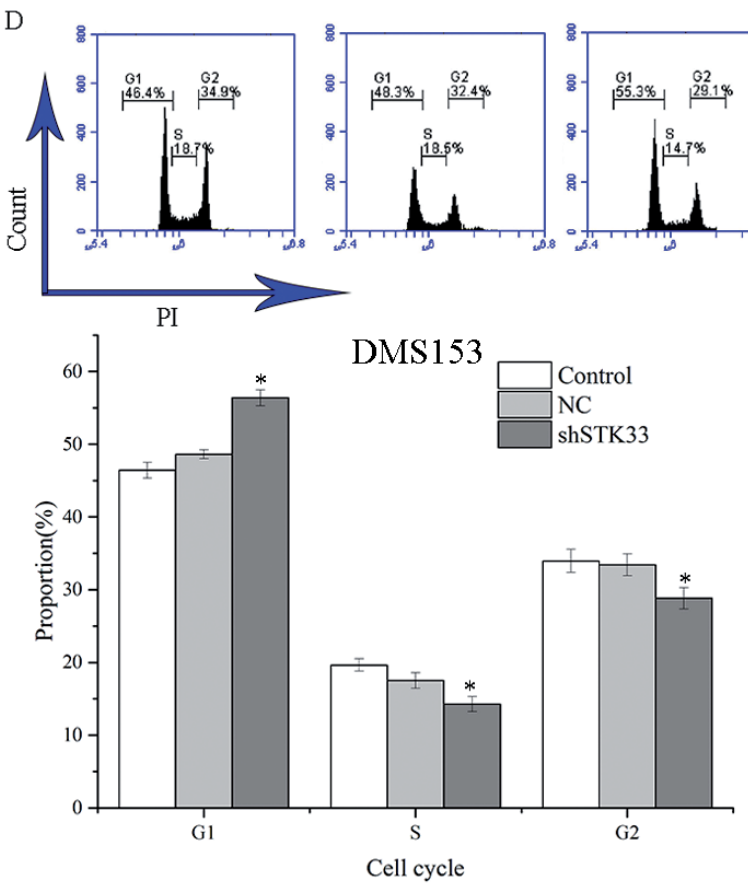

Figure 2. Knockdown of STK33 induced cell apoptosis and G1 cell cycle arrest in SCLC cells. A and C, representative images and quantitative analysis results of apoptotic rates of NCI-H446 and DMS153 cells. B, representative images and quantitative analysis results of cell cycle distribution in NCIH446 and DMS153 cells. “*”, significantly different from Control group, $P<0.05$. 
A
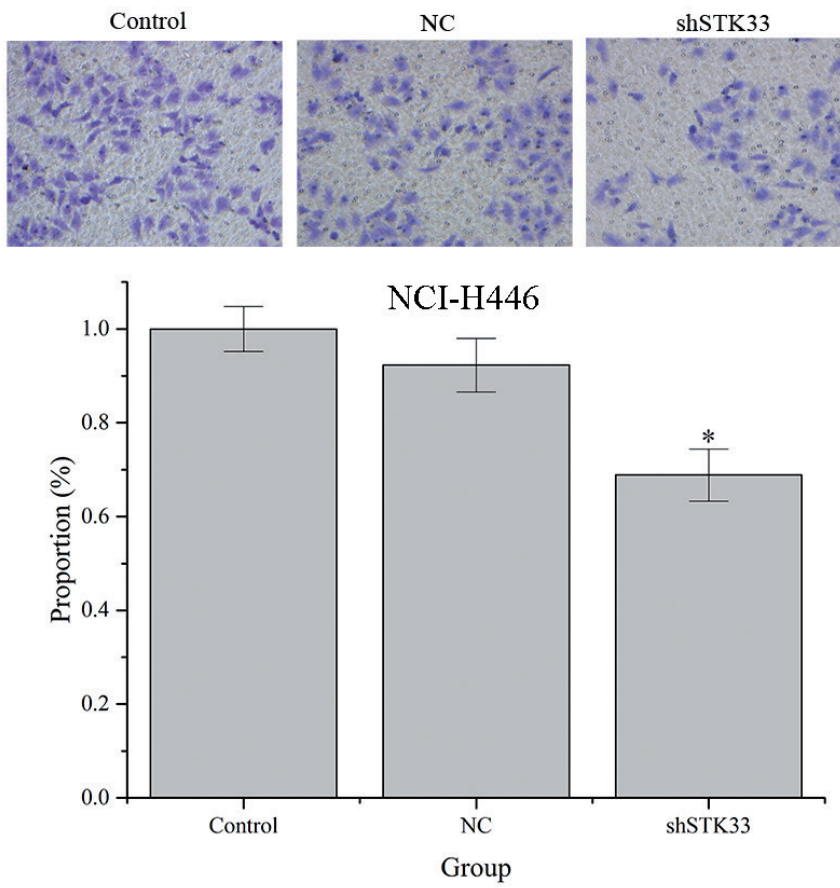

C

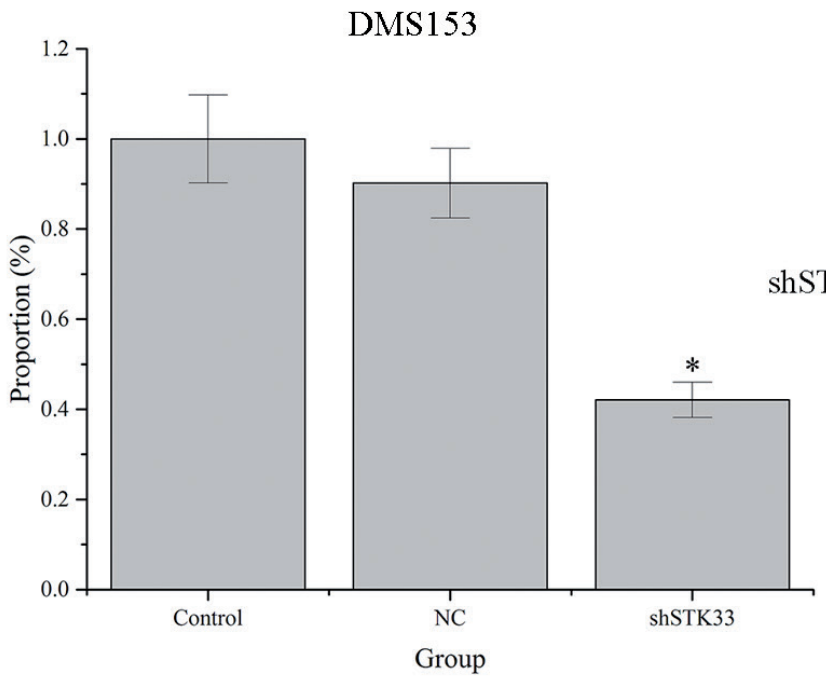

B

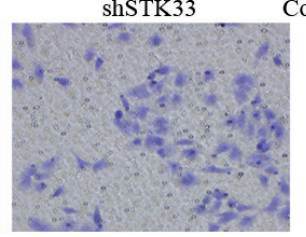

$\mathrm{NC}$

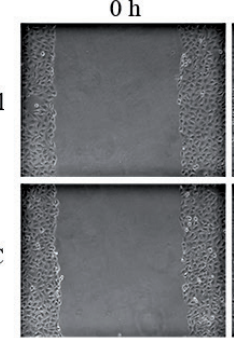

hSTK33

$24 \mathrm{~h}$

$48 \mathrm{~h}$
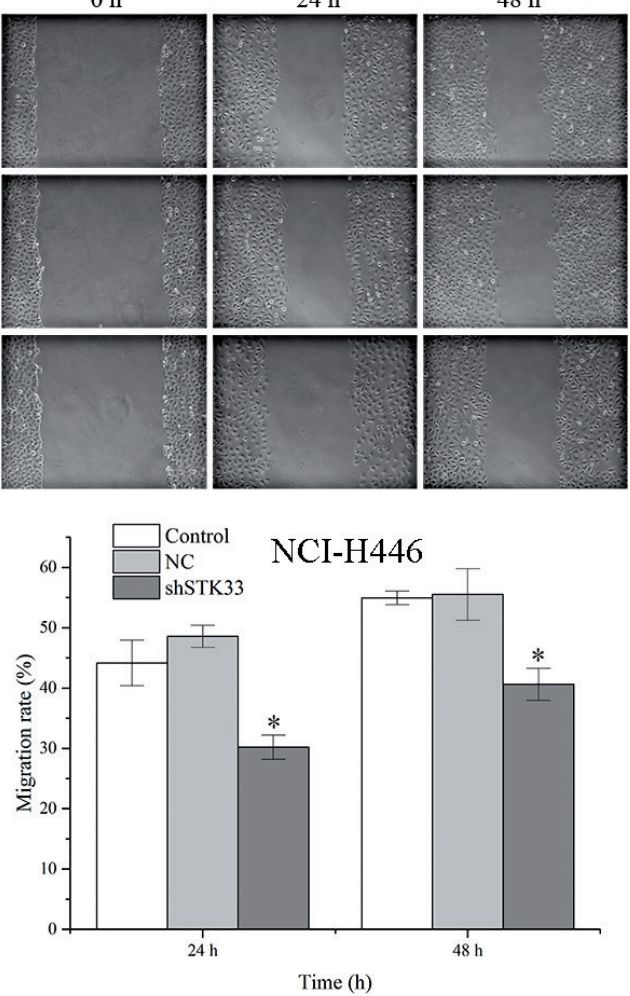

D
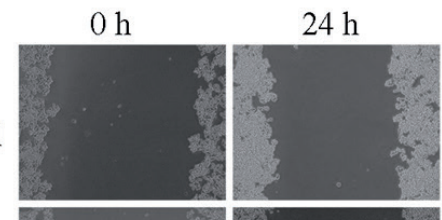

$48 \mathrm{~h}$

Control

$\mathrm{NC}$
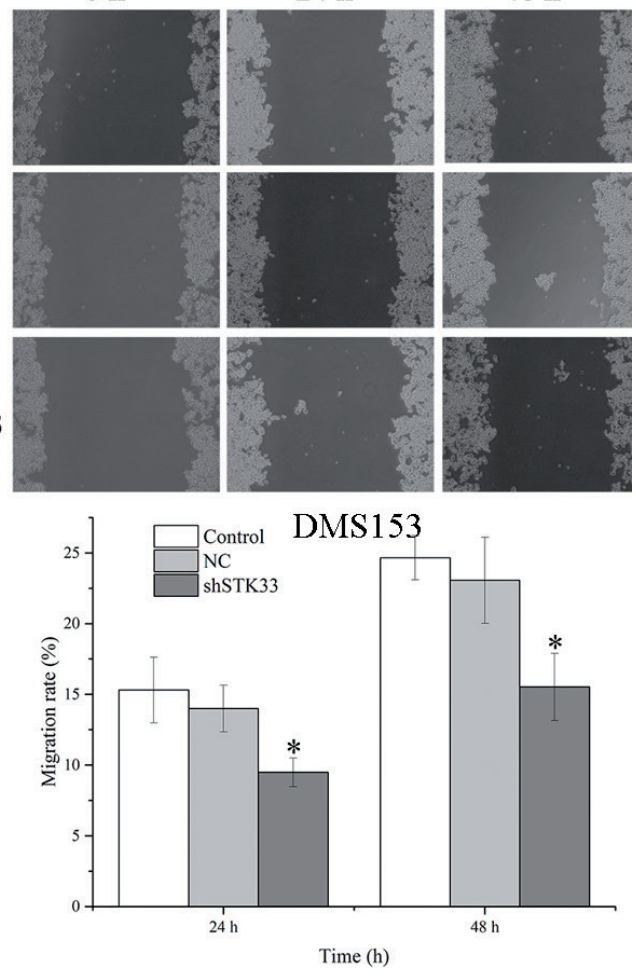

Figure 3. Knockdown of STK33 in SCLC cells inhibited cell invasion potential in SCLC cells. A, representative images and quantitative analysis results of transwell assays in in NCI-H446 cells. Magnification: 200×. B and D, representative images and quantitative analysis results of scratch assays in NCI-H446 and DMS153cells. C, quantitative analysis results of transwell assays in in DMS153cells. DMS153 cell line is a cell type with an incomplete adherence feature and images of transwell assay cannot be obtained. “*”, significantly different from Control group, $P<0.05$. 

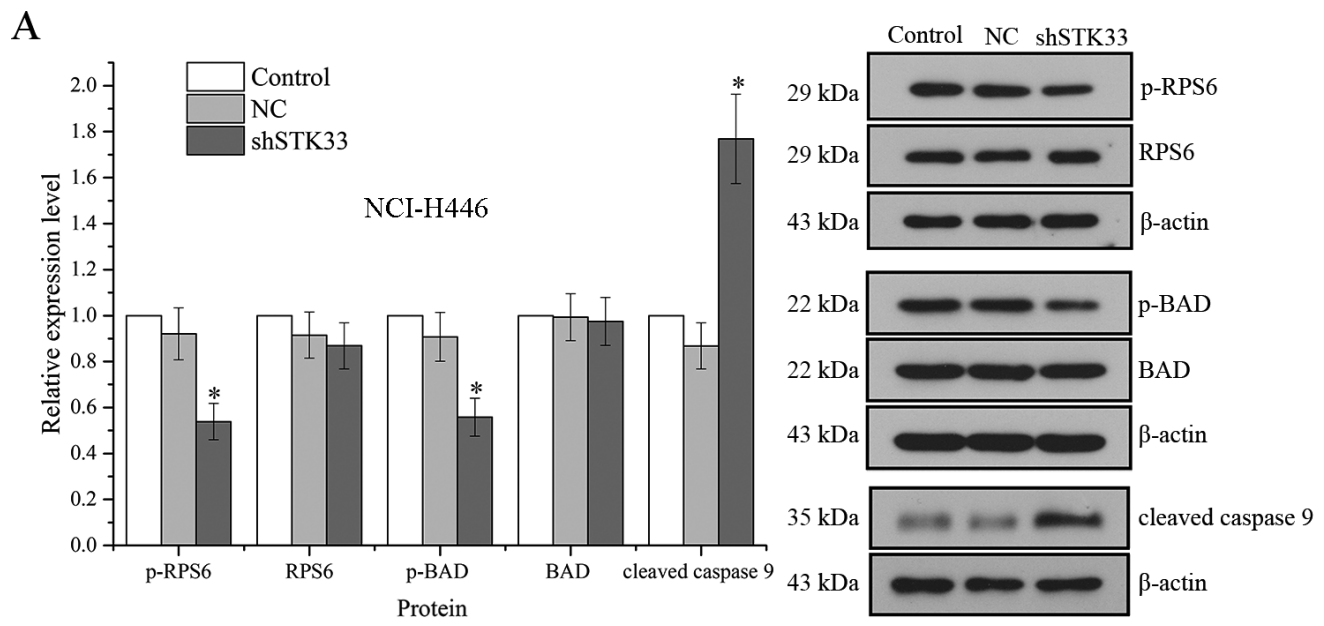

B

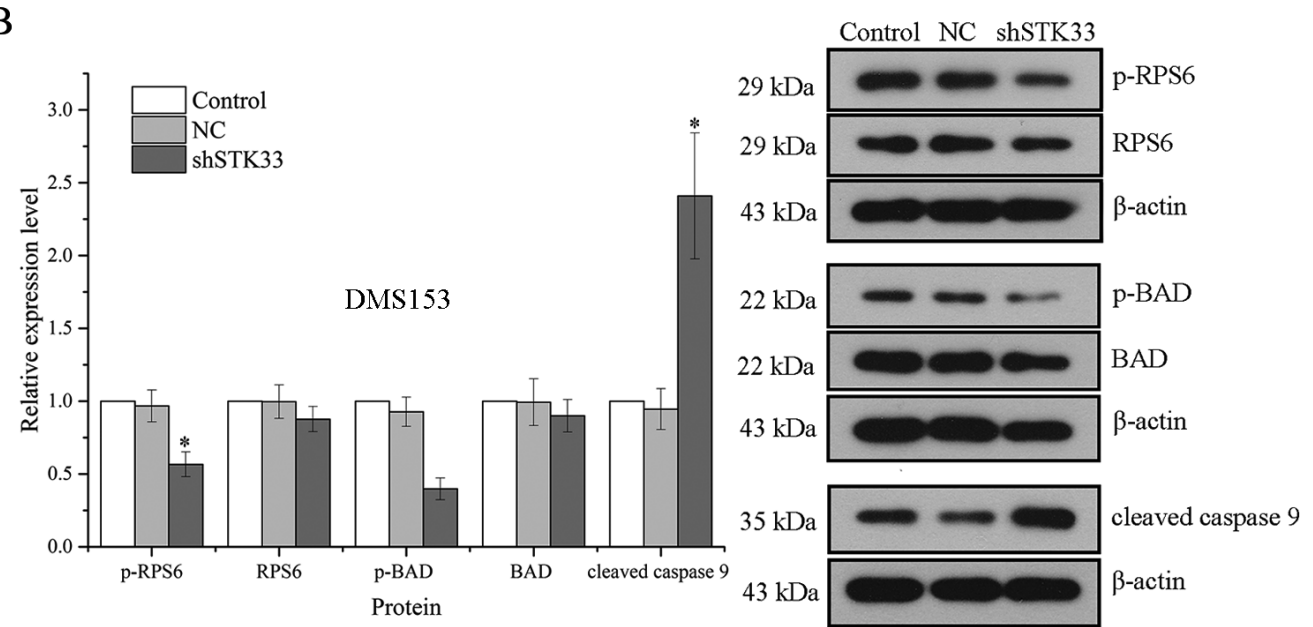

Figure 4. Knockdown of STK33 exerted its inhibiting effect on SCLC cells via inactivation of RPS6/BAD signaling transduction. “*”, significantly different from Control group, $P<0.05$.

related to this pathway was identical with previous reports: STK33 knockdown decreased the phosphorylation of RPS6 (Figure 4), a downstream effector of S6K1 required for ribosome biogenesis and protein synthesis. Knockdown of STK33 also inhibited the expression of p-BAD and had no influence on the total BAD (Figure 4). Moreover, STK33 knockdown induced the expression of cleavage caspase 9, which demonstrated that apoptosis induced by STK33 suppression was mediated via mitochondrial pathway. The role of STK33 in the oncogenesis was further validated by inhibiting its activity with ML281. As shown in Figure 5, inhibition of STK33 by specific inhibitor decreased the cell viability of NCI-H446 cells and showed a similar effect on RPS6/BAD to that of shRNA, which confirmed the conclusion that apoptosis induced by STK33 suppression was mediated via mitochondrial pathway.

Knockdown of STK33 limited SCLC growth by inhibiting RPS6/BAD signaling in a SCLC xenograft mice model. The results of in vitro assays were further tested in animal models.
As illustrated in Figure 6A, solid tumor could be detected seven days after NCI-H446 cell injection and in each group, the tumor volumes kept increasing until $22^{\text {nd }}$ days. For recording points since the $16^{\text {th }}$ day, the average volume in shSTK33 group was significantly lower than that in Control group or in NC group $(P<0.05)$. Validated by western blotting (Figure $6 \mathrm{~B})$, the expression levels of p-RPS6 and p-BAD in shSTK33 group were significantly lower than that in Control group or NC group $(P<0.05)$ and the expression of cleaved caspase 9 was up-regulated in shSTK33 group, which was consistent with the results of in vitro assays. Taken together, the results confirmed the key role of STK33 gene in the development of SCLC.

\section{Discussion}

The STK33 gene locates on chromosome 11, region 11p15.3, and consists of 12 introns and 1545 bp open-reading frame $[18,19]$, the expression status of which is limited in most hu- 
A

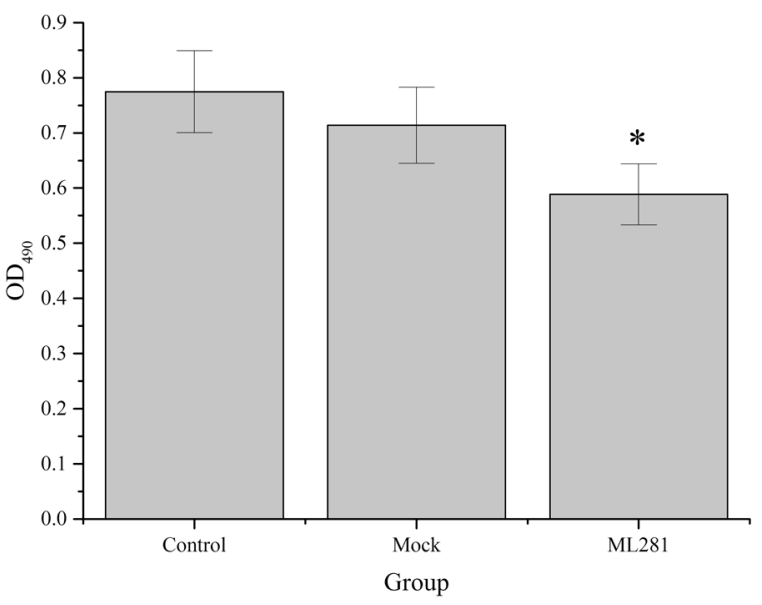

B

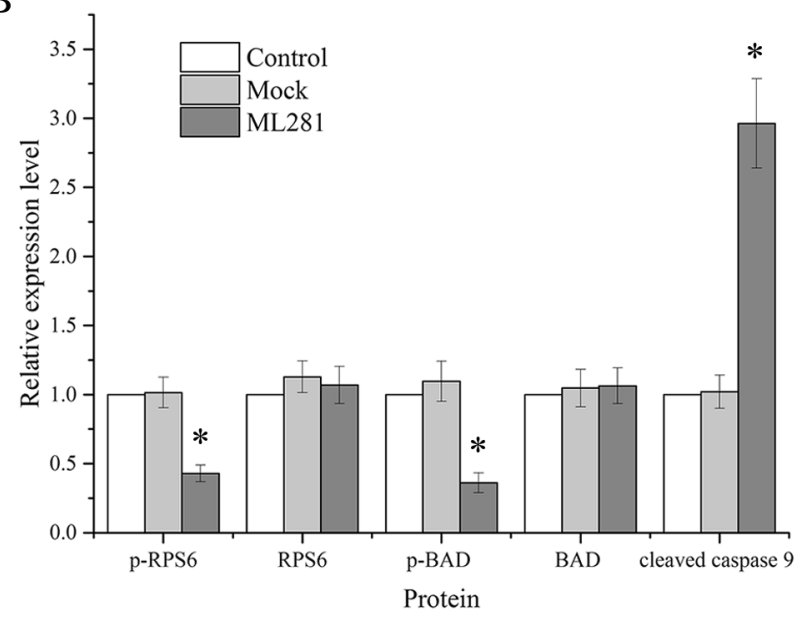

Control Mock ML281

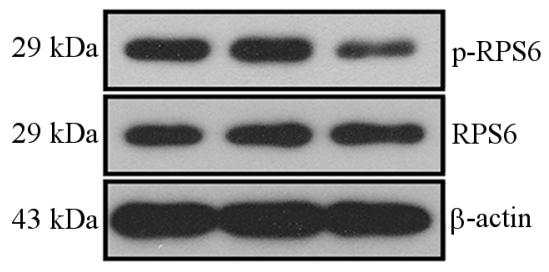

Control Mock ML281

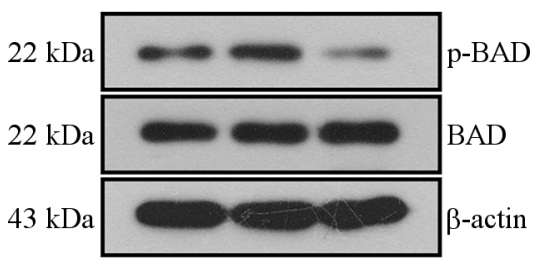

Control Mock ML281

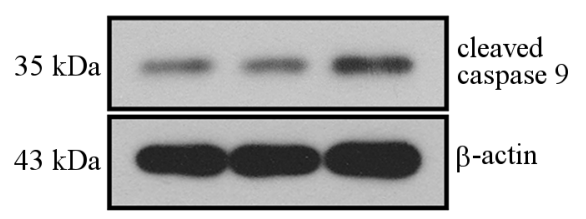

Figure 5. Suppression of STK33 by ML281 antagonizing NCI-H446 cells via inactivation of RPS6/BAD signaling transduction. A, cell viability of NCIH446 cells was suppressed by STK33 inhibitor ML281. B, representative images and analysis results of western blotting validation after incubation with ML281. "*”, significantly different from Control group, $P<0.05$.

man tissues except in testis, particularly in the spermatogenic epithelium [19]. Nevertheless, the abnormally high expression of STK33 is often detected in different types of cancers, including lung adenocarcinoma and large cell lung cancer [15, 16]. In the current study, the specific role of STK33 in another type of lung carcinoma, SCLC, was investigated and the results showed that STK33 was an important mediator for the survival, proliferation, and invasion of SCLC cells. Based on molecular evidence, the effect of STK33 on SCLC was exerted via RPS6/ BAD signaling pathway.

Oncogenesis and progression of cancers always involves many intricate hereditary and acquired genetic variations that are induced by a particular oncogene [20]. Therefore, purposeful inhibition of a gene involved in the onset of tumor can contribute to the suppression of tumor cell survival and differentiation. In the study of Wang et al., the authors infer that STK33 contributes to the migration and invasion of human large cell lung cancer cells and inhibition of the gene can certainly suppresses the migration and invasion of these cell lines [15]. Authors of this study also report that STK33 increases the expression of tumor-related genes, including Integrin, CXCR4, and CDC2, and decrease the expression of the tumor suppressor gene p53, confirming the role of STK33 as a mediator of tumor cell adhesion and migration [21-25]. Additionally, previous study of Scholl et al. infers that inhibition of STK33 in multiple KRAS-dependent cancer cell lines can result in synthetic lethal interactions [16]: the gene is capable of promoting cell viability in cancer cells in a kinase activity-dependent manner by suppressing of mitochondrial apoptosis through S6K1-induced inactivation of the death agonist BAD selectively. And as reported by the researchers, the STK33-S6K1 induced suppression of BAD is a novel mechanism whereby mutant KRAS-dependent cells evade apoptosis [16]. Generally, aberrant activity of S6K1 in tumors is initiated primarily in response to stimulation of the upstream regular mTORC1 [26], but Scoll et al. demonstrate that in KRAS-dependent cells, S6K1 activity is modulated by STK33 in a manner independent of mTORC1 or other related molecular components [16]. However, the STK33-S6K1 induced BAD suppression was majorly studied in KRASdependent cells, i.e., NSCLC. For SCLC, the mutant KRAS is not a required mechanism for the tumorigenicity of the cancer. Of the two cell lines employed in the current study, the model cell line NCI-H466 employed is characterized by redundant expression of c-Myc [27], which might infer a potential mechanism regulating the oncogenesis of SCLC. Thus, the detailed function of STK33-S6K1-BAD signaling in NCI-H466 cells is worthy of exploration to explain the mechanism driving the oncogenesis of SCLC. Based on the results of molecular detection, it was surprising to find that 
A

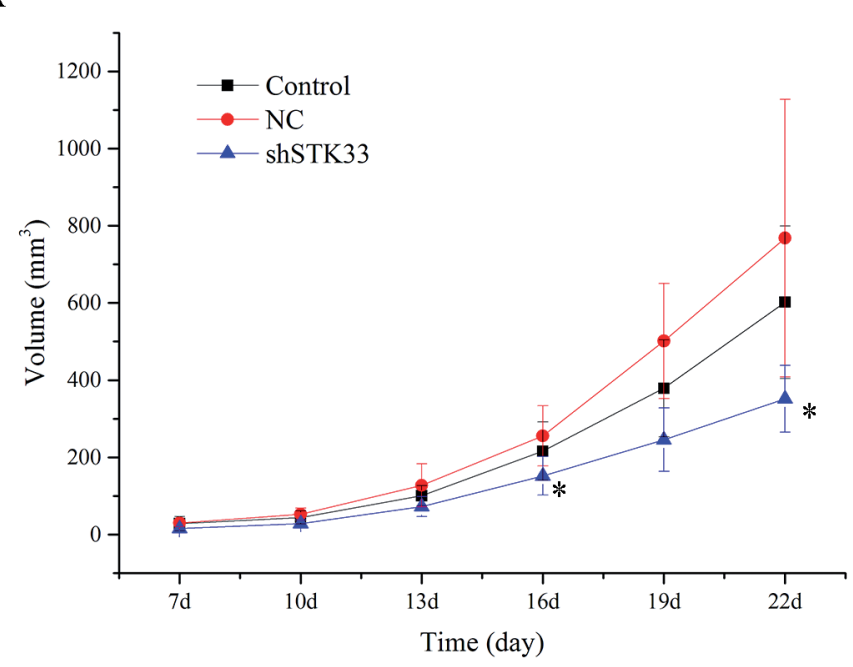

B

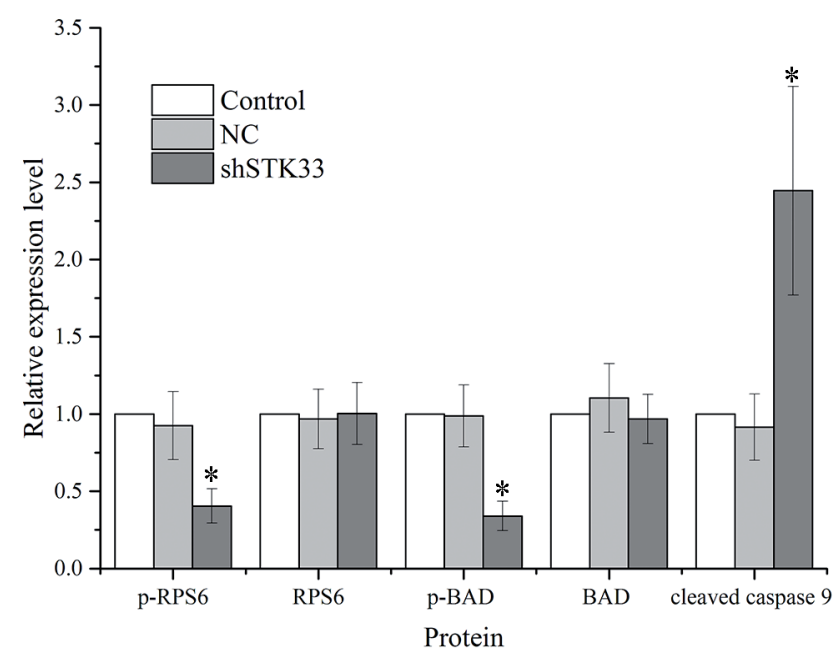

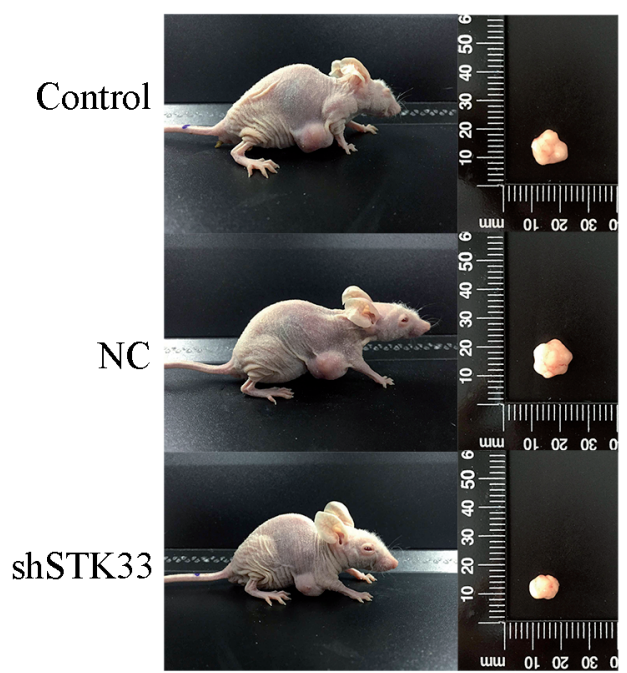

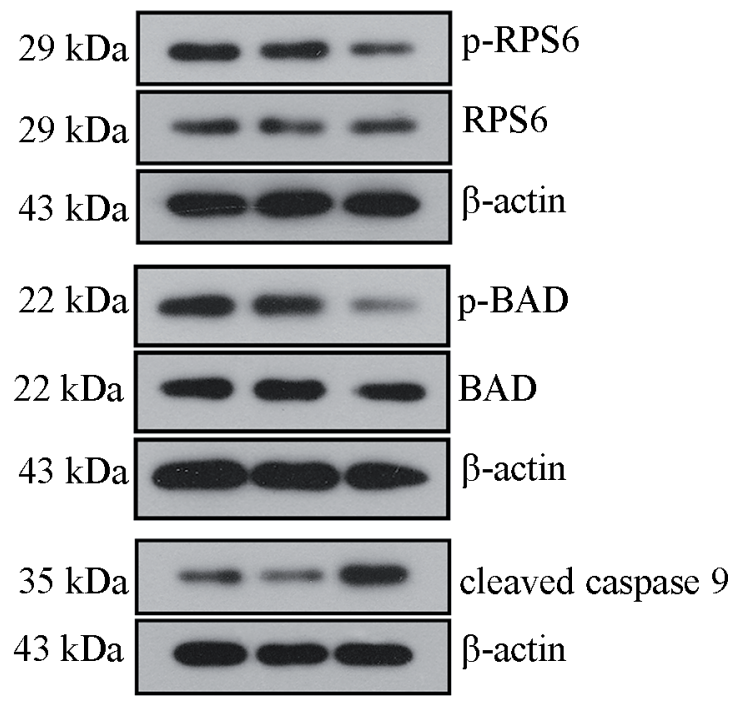

Figure 6. Knockdown of STK33 inhibited the growth of SCLC in vivo. A, quantitative analysis of growth curve of solid tumors in different groups, tumor volumes at the last three recording time points were significantly inhibited by knockdown of STK33. Images illustrated the morphology of solid tumors in different groups at $22^{\text {nd }}$ day. B, representative images and analysis results of western blotting validation in vivo. "*”, significantly different from Control group, $P<0.05$.

although knockdown of STK33 inhibited the expression of p-RPS6 and p-BAD and increased the expression of cleaved caspase 9, which indicated that the apoptosis induced by STK33 knockdown was modulated by mitochondrial pathway, the suppression of the gene had no effect on the activity of S6K1 in both SCLC cells. RPS6 is a downstream effector of $\mathrm{S} 6 \mathrm{~K} 1$ and is required for ribosome biogenesis and protein synthesis [28]. The molecule has been indicated as a surrogate marker of S6K1 activity. However, contrary to the results of Scoll et al. [16], the suppressed phosphorylation of RPS6 in the current study was not concomitant with the deactivation of S6K1. Although the function of S6K1 was not influenced by knockdown of STK33 in SCLC cells, inactivation of BAD was detected in our assays. Such results might represent the existence of other STK33 dependent pathways which regulates the activity of BAD. In addition, concomitant with the inhibition of STK33 function, the survival, proliferation, and invasion of SCLC cells was also suppressed. Taken together, although the mechanism of STK33 varied with cancer types, its potency as anti-lung cancer therapeutic target was evidently confirmed. Our findings were not only a complement to the role of STK33 in the oncogenesis and progression of SCLC but also inferred the cancer type specific function of STK33.

Conclusively, the current study for the first time demonstrated that STK33 played an important role in the 
development of SCLC. Specific inhibition of the gene suppressed the cell survival, cell proliferation, and cell invasion of SCLC cell lines. Although the mechanism driving the function of gene in SCLC was only preliminarily investigated in the current study, it was clearly different from that in NSCLC: knockdown of STK33 in SCLC cells induced the apoptosis through mitochondrial pathway but independent of S6K1 function. Based on the above results, the mechanism driving STK33 as biomarkers for guided therapeutic strategies varies with different lung carcinoma types.

Acknowledgements: This study was supported by a grant from the Science and Technology Development Project of Shandong Province (No. 2011GGH21820).

\section{References}

[1] TORRE LA, BRAY F, SIEGEL RL, FERLAY J, LORTETTIEULENT J et al. Global cancer statistics, 2012. CA Cancer J Clin 2015; 65: 87-108. https://doi.org/10.3322/caac.21262

[2] FERLAY J, SHIN HR, BRAY F, FORMAN D, MATHERS C et al. Estimates of worldwide burden of cancer in 2008: GLOBOCAN 2008. Int J Cancer 2010; 127: 2893-2917. https://doi. org/10.1002/ijc.25516

[3] KAMANGAR F, DORES GM, ANDERSON WF. Patterns of cancer incidence, mortality, and prevalence across five continents: defining priorities to reduce cancer disparities in different geographic regions of the world. J Clin Oncol 2006; 24: 2137-2150. https://doi.org/10.1200/ LCO.2005.05.2308

[4] VAN MEERBEECK JP, FENNELL DA, DE RUYSSCHER DK. Small-cell lung cancer. Lancet 2011; 378: 1741-1755. https:// doi.org/10.1016/S0140-6736(11)60165-7

[5] KATO Y, FERGUSON TB, BENNETT DE, BURFORD TH. Oat cell carcinoma of the lung. A review of 138 cases. Cancer 1969; 23: 517-524. https://doi.org/10.1002/10970142(196903)23:3<517::AID-CNCR2820230301>3.0.CO;2-L

[6] JACKMAN DM, JOHNSON BE. Small-cell lung cancer. Lancet 2005; 366: 1385-1396. https://doi.org/10.1016/S01406736(05)67569-1

[7] WISTUBA, II, BEHRENS C, VIRMANI AK, MELE G, MILCHGRUB S et al. High resolution chromosome 3p allelotyping of human lung cancer and preneoplastic/preinvasive bronchial epithelium reveals multiple, discontinuous sites of $3 \mathrm{p}$ allele loss and three regions of frequent breakpoints. Cancer Res 2000; 60: 1949-1960.

[8] TAKAHASHI T, NAU MM, CHIBA I, BIRRER MJ, ROSENBERG RK et al. p53: a frequent target for genetic abnormalities in lung cancer. Science 1989; 246: 491-494. https://doi. org/10.1126/science.2554494

[9] WISTUBA, II, BERRY J, BEHRENS C, MAITRA A, SHIVAPURKAR $\mathrm{N}$ et al. Molecular changes in the bronchial epithelium of patients with small cell lung cancer. Clin Cancer Res 2000; 6: 2604-2610.

[10] HARBOUR JW, LAI SL, WHANG-PENG J, GAZDAR AF, MINNA JD et al. Abnormalities in structure and expression of the human retinoblastoma gene in SCLC. Science 1988; 241: 353-357. https://doi.org/10.1126/science. 2838909

[11] GEORGE J, LIM JS, JANG SJ, CUN Y, OZRETIC L et al. Comprehensive genomic profiles of small cell lung cancer. Nature 2015; 524: 47-53. https://doi.org/10.1038/ $\underline{\text { nature } 14664}$

[12] Otterson G, Lin A, Kay F. Genetic etiology of lung cancer. Oncology (Williston Park) 1992; 6: 97-104.

[13] MANNING G, WHYTE DB, MARTINEZ R, HUNTER T, SUDARSANAM S. The protein kinase complement of the human genome. Science 2002; 298: 1912-1934. https://doi. org/10.1126/science.1075762

[14] YANG T, SONG B, ZHANG J, YANG G-S, ZHANG H et al. STK33 promotes hepatocellular carcinoma through binding to c-Myc. Gut 2016; 65: 124-133. https://doi.org/10.1136/ gutjnl-2014-307545

[15] WANG P, CHENG H, WU J, YAN A, ZHANG L. STK33 plays an important positive role in the development of human large cell lung cancers with variable metastatic potential. Acta Biochim Biophys Sin (Shanghai) 2015; 47: 214-223. https:// doi.org/10.1093/abbs/gmu136

[16] SCHOLL C, FROHLING S, DUNN IF, SCHINZEL AC, BARBIE DA et al. Synthetic lethal interaction between oncogenic KRAS dependency and STK33 suppression in human cancer cells. Cell 2009; 137: 821-834. https://doi.org/10.1016/j. cell.2009.03.017

[17] BABIJ C, ZHANG Y, KURZEJA RJ, MUNZLI A, SHEHABELDIN A et al. STK33 kinase activity is nonessential in KRAS-dependent cancer cells. Cancer Res 2011; 71: 5818-5826. https://doi.org/10.1158/0008-5472.CAN-11$\underline{0778}$

[18] MUJICA AO, HANKELN T, SCHMIDT ER. A novel serine/ threonine kinase gene, STK33, on human chromosome 11p15.3. Gene 2001; 280: 175-181. https://doi.org/10.1016/ S0378-1119(01)00780-6

[19] MUJICA AO, BRAUKSIEPE B, SAALER-REINHARDT S, REUSS S, SCHMIDT ER. Differential expression pattern of the novel serine/threonine kinase, STK33, in mice and men. FEBS J 2005; 272: 4884-4898. https://doi.org/10.1111/j.17424658.2005.04900.x

[20] WEINSTEIN IB. Addiction to oncogenes--the Achilles heal of cancer. Science 2002; 297: 63-64. https://doi.org/10.1126/ science. 1073096

[21] Muller A, HOMEY B, Soto H, GE N, CATroN $\mathrm{D}$ et al. Involvement of chemokine receptors in breast cancer metastasis. Nature 2001; 410: 50-56. https://doi. org/10.1038/35065016

[22] ZLOTNIK A. New insights on the role of CXCR4 in cancer metastasis. J Pathol 2008; 215: 211-213. https://doi.org/10.1002/ path. 2350

[23] O'CONNOR DS, WALL NR, PORTER ACG, ALTIERI DC. A p34 cdc2 survival checkpoint in cancer. Cancer Cell 2002; 2: 43-54. https://doi.org/10.1016/S1535-6108(02)00084-3

[24] MULLER PAJ, VOUSDEN KH. Mutant p53 in cancer: new functions and therapeutic opportunities. Cancer Cell 2014; 25: 304-317. https://doi.org/10.1016/j.ccr.2014.01.021 
[25] HONG B, VAN DEN HEUVEL PJ, V PRABHU V, ZHANG $S$, EL-DEIRY WS. Targeting tumor suppressor p53 for cancer therapy: strategies, challenges and opportunities. Curr Drug Targets 2014; 15: 80-89. https://doi.org/10.2174/1389450114 $\underline{666140106101412}$

[26] GUERTIN DA, SABATINI DM. Defining the role of mTOR in cancer. Cancer Cell 2007; 12: 9-22. https://doi.org/10.1016/j. ccr.2007.05.008
[27] ZHANG Z, ZHOU Y, QIAN H, SHAO G, LU X et al. Stemness and inducing differentiation of small cell lung cancer NCI-H446 cells. Cell Death Dis 2013; 4: e633. https://doi. org/10.1038/cddis.2013.152

[28] RUVINSKY I, MEYUHAS O. Ribosomal protein S6 phosphorylation: from protein synthesis to cell size. Trends Biochem Sci 2006; 31: 342-348. https://doi.org/10.1016/j. tibs.2006.04.003 
A

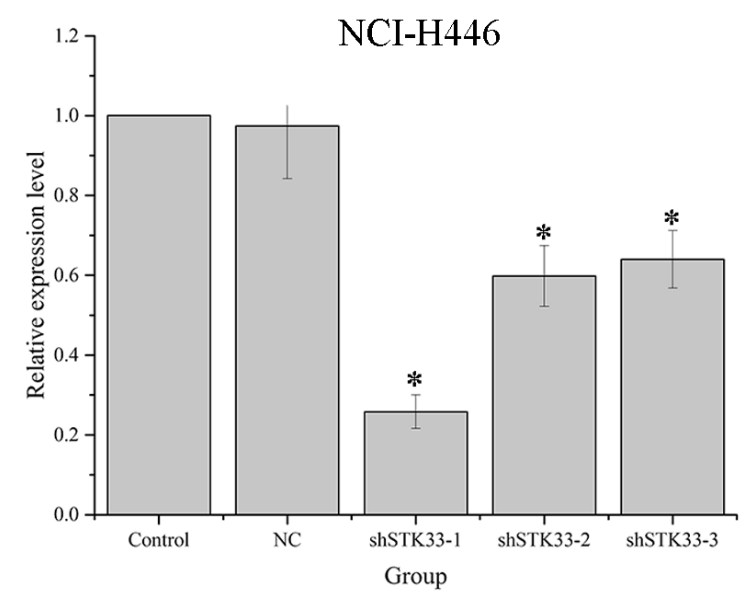

C

\section{DMS153}

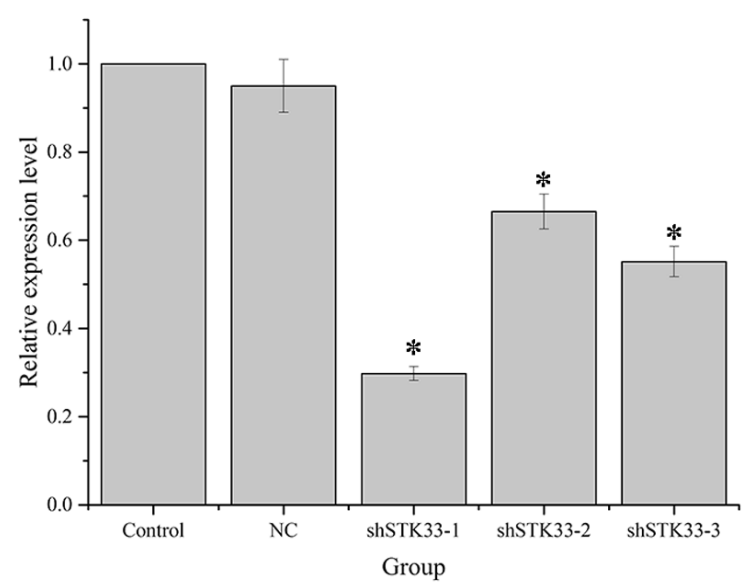

B

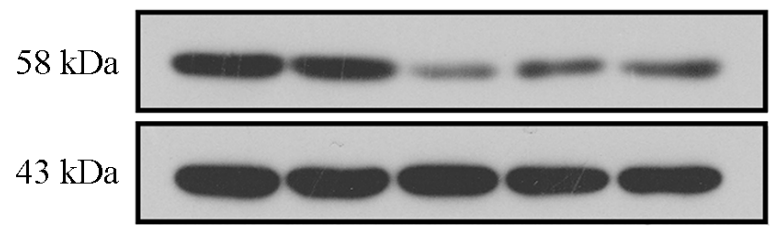

STK 33

$\beta$-actin

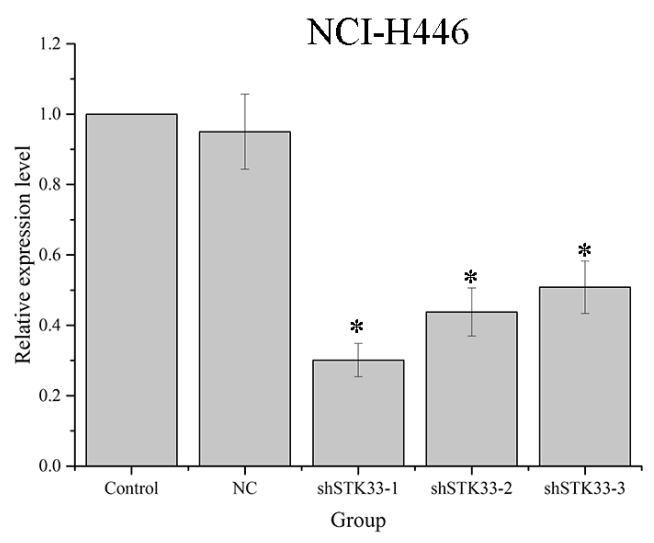

D
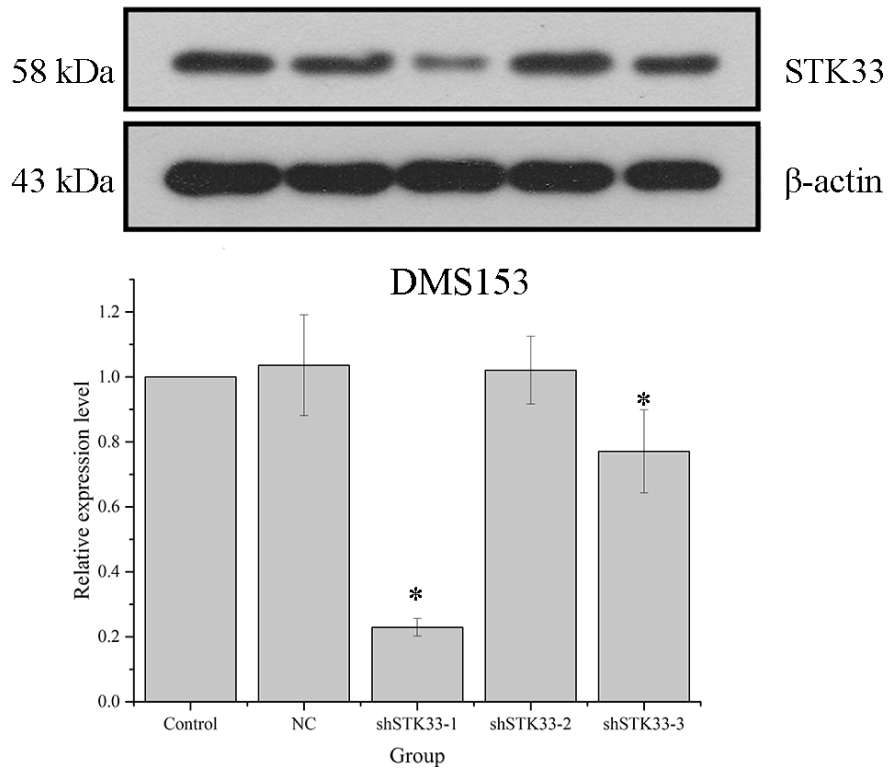

Supplementary Figure S1. Validation of expression change of STK33 in SCLC cells transfected with pRNA-H1.1-shSTK33 plasmid. A and C, quantitative analysis results of RT2-PCR, the expression of STK33 was suppressed both in NCI-H466 and DMS153 cells post transfection of pRNA-H1.1-shSTK33. A, representative images and quantitative analysis results of western blotting, the expression of STK33 was suppressed both in NCI-H466 and DMS153 cells post transfection of pRNA-H1.1-shSTK33. “*”, significantly different from control group, $\mathrm{P}<0.05$. 